\section{Bile duct cancers: What can EUS offer? Intraductal US, 3D-IDUS? FNA - is it possible?}

K. Inui, H. Miyoshi, J. Yoshino

Department of Internal Medicine, Second Teaching Hospital, Fujita Health University School of Medicine, Nagoya, Japan

\section{Introduction}

An international workshop on the clinical impact of endoscopic ultrasound in gastroenterology in conjunction with the $12^{\text {th }}$ international symposium on endoscopic ultrasonography, held in Monaco in 2000. In the workshop, new indications for EUS in the biliary tract were discussed [1]. The major application of EUS in biliary tract cancers concerns tumor staging. Accurate diagnosis of cancer extension is necessary for adequate surgical procedures. Intraductal ultrasonography (IDUS) is a reliable method that can be used for more detailed evaluation of bile duct cancer. We reported the usefulness of three-dimensional intraductal ultrasonography (3D-IDUS) for comprehensive evaluation of extension of biliary tract tumors [2]. Although EUS-guided fine needle aspiration (FNA) is performed usually in pancreatic tumors, it is not standardized in biliary tract tumors. In this report, we reviewed the usefulness of EUS, IDUS, 3D-IDUS and EUSFNA for diagnosis and treatment of bile duct cancers.

\section{What can EUS offer for diagnosis of bile duct cancers?}

Because EUS reveals the extrahepatic bile ducts in almost all patients, it is the most reliable method for diagnosis of obstructive

Correspondence: Kazuo Inui, M.D. · Department of Internal Medicine · Second Teaching Hospital · Fujita Health University School of Medicine · 3-6-10, Otobashi, Nakagawa-ku, Nagoya 454-8509 · Japan · Phone: +81-52-321-8171 · Fax: +81-52-323-9886

Bibliography: Endoscopy 2006; 38 (S1): S47-S49 @ Georg Thieme Verlag KG Stuttgart · New York · ISSN 0013-726X · DOI 10.1055/s-2006-946651 jaundice. However, the depth of field is limited so that the exploration of the hilum is generally not possible. When we suspect a biliary disease, we always use conventional ultrasonography (US) as the first diagnostic imaging. When US revealed an extrahepatic obstructive jaundice, what kind of examination is performed? EUS had proved as a gold standard in the exploration of extrahepatic obstruction due to its low morbidity and its accuracy $[3,4]$. However, other radiological examinations are recently developed for the diagnosis of the biliary tract, multi-detectorrow CT (MD-CT) and magnetic resonance cholangiopancreatography (MRCP). These procedures appear to have advantages because they are non-invasive and able to simultaneously depict the whole biliary tract, the pancreatic duct and the liver and pancreas. However, CT and MRCP are limited for the exploration of small lesions $[5,6]$. Therefore, EUS is still the best procedure for the diagnosis of biliary obstruction, as well as the most accurate when diagnosing extrahepatic obstruction and staging tumors. EUS can offer a precise diagnosis and staging of biliary tract tumors $[7,8]$. Although EUS offer a precise diagnosis in the middle and distal segments of the biliary tract, MRCP and direct cholangiography (ERC or PTC) are better than EUS in the proximal region.

\section{What can IDUS and 3D-IDUS offer?}

IDUS using a high-frequency ultrasonic miniature probe is accurate for diagnosing biliary strictures [9] and staging of bile duct cancers. IDUS was reported the limitation for tight stenosis [10]. However, miniature ultrasonic probe have been developing. The ultrasonic probe with ropeway system increased success rate in transpapillary approach [11]. Using the ropeway system with a guide-wire, scanning of the bile duct was achieved in 98.2 to $99.2 \%$ of the patients, regardless of the site and length of the biliary strictures. Once the guide-wire passed through the biliary stenosis, no further technique like endoscopic sphincterotomy or dilatation of stenosis is required to introduce the ultrasonic probe (Fig. 1A, 1B).

Menzel et al. [12] reported the usefulness of IDUS for diagnosis of bile duct cancers, tumor extent was diagnosed correctly in $76.8 \%$ of cases when using IDUS and in 53.6\% cases in EUS. For hilar-hepatic tumors, EUS has limitations for diagnosis and staging, but IDUS is accurate for staging [13]. IDUS is useful to demonstrate clearly invasion of the pancreas or portal vein $[14,15]$. However, it is difficult to diagnose histological infiltration of the fibrous layer of the peri-muscular loose connective tissue in T1 tumors [16].

We performed IDUS since 1989 and 3D-IDUS since 1995 [15,17]. Since 1997 , we usually used a ropeway system probe UM5RG29R, $2.9 \mathrm{~mm}$ in diameter, developed by Olympus Medical Systems (Tokyo, Japan), incorporated a radial scanning system with a frequency of $20 \mathrm{MHz}$. The probe was connected to an endoscopic ultrasonic observation unit (EU-M30, or EU-M2000; Olympus Medical Systems). The probe was easily passed through the $2.8 \mathrm{~mm}$ diameter biopsy channel of the duodenoelectronic scope (JF-200, JF230, or TJF 200; Olympus Medical Systems). We used a 3DIDUS system, developed by Olympus Medical Systems; an ultrasound image processing unit, EU-IP2; a 3D ultrasonic probe, UM3D-3R (20 MHz), with a diameter of $3.4 \mathrm{~mm}$; and a probe driving 
unit, MAJ-355, since 1995. These were connected to an endoscopic ultrasonic observation unit (EU-M30 or EU-M2000).

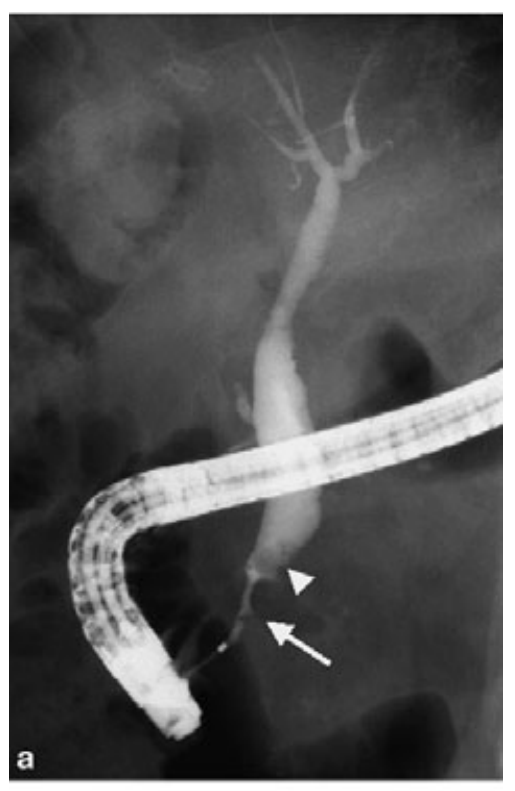

Fig. 1 a Endoscopic retrograde cholangiopancreatography reveals an irregular stenosis (arrow) of the distal common bile duct and a filling defect (arrow head). b An ultrasonic probe is inserted into the bile duct along with a guide-wire through a biopsy-channel of a duodenoscope. CD, cystic duct.
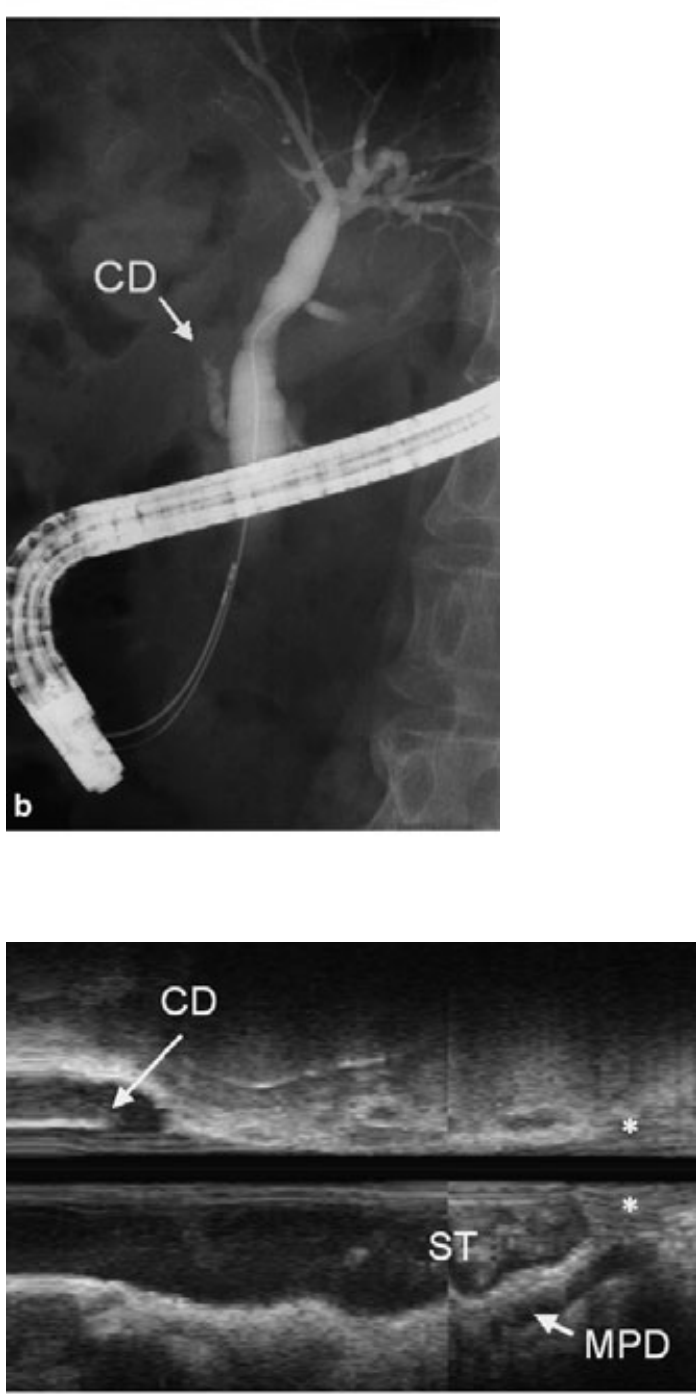

Fig. 2 3D-IDUS of bile duct carcinoma; a composite sonogram of two sessions reveals a hypo-echoic mass $\left({ }^{*}\right)$ and stone (ST) in the distal end of the common bile duct. CD, cystic duct, MPD, main pancreatic duct.
We could observe the bile duct wall as two to three layers. On the other hand, IDUS revealed a lesion of carcinoma as an image of low echoic, irregular thickness. When the tumor echogram reached the high echoic layer of the bile duct, we could diagnose that the tumor had invaded the subserosa. When the tumor echogram reached the parenchyma of the pancreas, it could be diagnosed that the pancreas had been invaded. The important findings to diagnose tumor invasion to the pancreas is a high echoic layer between the bile duct and the pancreas. When the tumor echogram reached the high echoic wall of the portal vein, it could be diagnosed that the portal vein had been invaded. The results of IDUS and pathological studies for tumor extension in 15 patients bile duct carcinoma were investigated. Over all accuracy for depth of tumor invasion was $93.3 \%$, for tumor invasion of the pancreas was $86.7 \%$, and invasion of the portal vein was $93.3 \%$. The accuracy of IDUS in assessing tumor invasion to the pancreas was reported 88.9 to100\% $[2,13,18,19]$. The accuracy of IDUS in assessing tumor invasion to the right hepatic artery and portal vein was 92.3 to $100 \%[2,13,18,19]$.

We could produce longitudinal reconstruction images (Fig. 2) with using the functions of the 3D-IDUS systems, dual plane reconstruction (DPR) images (Fig. 3), including radial and longitudinal reconstruction images and oblique reconstruction images (Fig. 4). DPR and oblique reconstruction images are useful to assess the tumor extension and the relationship with surrounding organs. 3D-IDUS is useful for the precise diagnosis of cancer extension in bile duct cancers, especially in invasion into the portal vein and pancreas. The other advantage of 3D-IDUS is that the time required for the examinations is reduced compared with that required for conventional IDUS, because conventional IDUS needs to clarify the relationship between lesions and surrounding organs and vessels.

Intraductal spreading of tumor is known as one of the characteristics of tumor extension of extrahepatic bile duct carcinoma. When the irregular thickness of the bile duct is observed consecutively and away from the main lesion, it could be diagnosed that intraductal spreading of cancer existed. The results of 3D-IDUS and pathological diagnosis for intraductal tumor spreading were studied in 11 patients on whom surgery was performed. Over all accuracy of 3D-IDUS for intraductal tumor spreading was only $70.0 \%$. The result was not satisfied as Tamada et al. [16] reported limitation of 3D-IDUS in the assessment of longitudinal spread. Other problem of IDUS and 3D-IDUS for diagnosis of bile duct cancer is limitations in diagnosis of lymph node metastasis [20]. Menzel et al. [21] reported that when each depictable lymph node was considered to be suggestive of malignancy, with regard to $\mathrm{N}$-staging, EUS was significantly superior to IDUS ( $64.9 \%$ vs. $33.3 \%$ ).

FNA - is it possible?

EUS guided cholangiography was reported at first by Wiersema et al. [22] in 1996. The procedure was used for selective opacification of biliary ducts under direct EUS guidance. They obtained a successful cholangiopancreatography in 8 out of 11 patients. The procedure is useful for patients in which ERCP had been unsuccessful. 

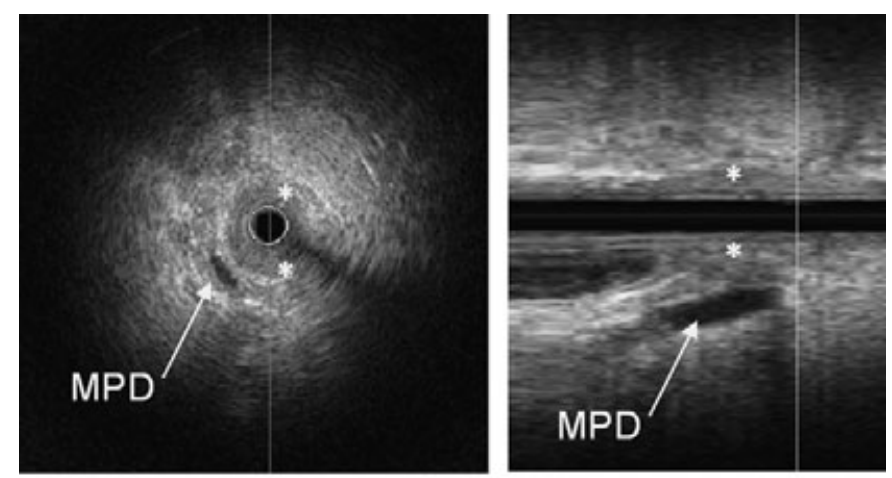

Fig. 3 DPR images, including radial and longitudinal reconstruction images, reveal easily the relationship between the tumor $\left({ }^{*}\right)$ and the main pancreatic duct (MPD).

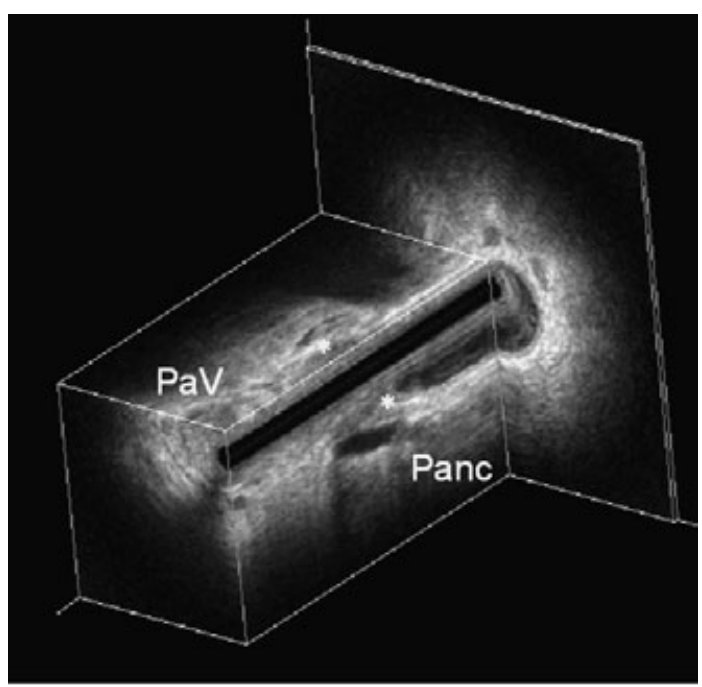

Fig. 4 Oblique reconstruction images reveal comprehensively the relationship between the tumor $\left({ }^{*}\right)$ and the pancreas (Panc). PaV, papilla of Vater.

EUS-guided fine-needle aspiration cytology is reported as a safe and accurate method for diagnosis of hilar cholangiocarcinoma $[23,24]$. This technique may represent a new approach to diagnosis when other method, like brush cytology, fail [24,25]. The practice of EUS-FNA has improved the diagnostic yield of EUS [26]. EUS-FNA is a new, exciting technique, and may become a essential procedure for conclusive diagnosis of bile duct carcinoma suspected with other imaging modality.

\section{References}

${ }^{1}$ Lambert R, Caletti G, Cho E, Chang KJ, Fusaroli P, Feussner H et al. International workshop on the clinical impact of endoscopic ultrasound in gastroenterology. Endoscopy 2000; 32: 549-584

2 Inui K, Yoshino J, Okushima K, Miyoshi H, Nakamura Y. Intraductal EUS. Gastrointest Endosc 2002; 56: 58-62

${ }^{3}$ Amouyal P, Palazzo L, Amouyal G, Ponsot P, Monpint D, Vilgrain V et al. Endosonography: promising method for diagnosis of extrahepatic cholestasis. Lancet 1989; ii: 1195 - 1198

${ }^{4}$ Dancygier GH, Natermann C. The role of endoscopic ultrasonography in biliary tract diseases: obstructive jaundice. Endoscopy 1994; 26: $800-802$
${ }^{5}$ Fulcher AS, Turner MA, Capps G, Zfass AM, Baker KM. Half-Fourier RARE MRCP: Experience in 300 subjects. Radiology 1998; 207: 21 32

${ }^{6}$ Bret PM, Reinhold C. Magnetic Resonance Cholangiopancreatography. Endoscopy 1997; 29: $72-486$

${ }^{7}$ Cannon ME, Carpenter SL, Elta GH, Nostrant TT, Kochman ML, Ginsberg GG et al. EUS compared with CT, magnetic resonance imaging, and angiography and the influence of biliary stenting on staging accuracy of ampullary neoplasms. Gastrointest Endosc 1999; 50: 27-33

${ }^{8}$ Tio TL, Cheng J, Wijers OB, Sars PRA, Tytgat GNJ. Endosonographic TNM staging of extrahepatic bile duct cancer: comparison with pathological staging. Gastroenterology 1991; 100: 1351 - 1361

${ }^{9}$ Fujita N, Noda Y, Kobayashi G, Kimura K, Yago A. Staging of bile duct carcinoma by EUS and IDUS. Endoscopy 1998; 30 (Suppl 1): A132134

${ }^{10}$ Stavropoulos S, Larghi A, Verna E, Battezzati P, Stevens P. Intraductal ultrasound for the evaluantion of patients with biliary strictures and no abdominal mass on computed tomography. Endoscopy 2005; 37 : $715-721$

${ }^{11}$ Fujita N, Noda Y, Yokohata K, Tanaka M, Maguchi H, Komatsu Y et al. Newly developed ultrasonic probe with ropeway system for transpapillary intraductal ultrasonography of the bilio-pancreatic ductal system. Dig Endosc 2000; 32: 250-254

${ }^{12}$ Menzel J and Dosmschke W. Intraductal ultrasonography (IDUS) of the pancreato-biliary duct system. Personal experience and review of literature. European J Ultrasound 1999; 10: 105-109

${ }^{13}$ Tamada K, Ido K, Ueno N, Kimura K, Ichiyama M, Tomiyama T. Preoperative staging of extrahepatic bile duct cancer with intraductal ultrasonography. Am J Gastroenterol 1995; 90: 239-246

${ }^{14}$ Gillams AR, Lees WR. Recent developments in biliary tract imaging. Gastrointest Endosc Clin N A 1996; 6: 1-15

${ }^{15}$ Inui K, Nakazawa S, Yoshino J, Wakabayashi T, Okushima K, Nakamura Y et al. Ultrasound probes for biliary lesions. Endoscopy 1998; 30 (SUppl 1): A $120-123$

${ }^{16}$ Tamada K, Kanai N, Ueno N, Ichiyama M, Tomiyama T, Wada S et al. Limitation of intraductal ultrasonography in differentiating between bile duct cancer in stage T1 and stage T2: in-vitro and in-vivo studies. Endoscopy 1997; 29: 721 - 725

${ }^{17}$ Kanemaki N, Nakazawa S, Inui K, Yoshino J, Yamao K, Okushima K. Three-dimensional intraductal ultrasonography: preliminary results of a new technique for the diagnosis of diseases of the pancreatobiliary system. Endoscopy 1997; 29: 726-731

${ }^{18}$ Kuroiwa M, Goto H, Hirooka Y, Furukawa T, Hayakawa T, Naitoh Y. Intraductal ultrasonography for the diagnosis of proximal invasion in extrahepatic bile duct cancer. J Gastroenterol Heatology. 1998; 13: $715-719$

${ }^{19}$ Tamada K, Ido K, Ueno N, Ichiyama M, Tomiyama T, Nishizono T et al. Assessment of the pancreatic parenchymal invasion in bile duct cancer by intraductal ultrasonography. Endoscopy 1996; 28: $492-496$

${ }^{20}$ Tamada K, Inui K, Menzel J. Intraductal ultrasonography of the bile duct system. Endoscopy 2001; 33: 878-885

${ }^{21}$ Menzel J, Poremba C, Dietl KH, Domschke W. Preoperative diagnosis of bile duct strictures - Comparison of intraductal ultrasonography with conventional endosonography. Scand J Gastroenterol 2000; 35: 77 82

${ }^{22}$ Wiersema MJ, Sandusky D, Carr R, Wiersema LM, Erdel WC, Frederic PK. Endosonography-guided cholangiopancreatography. Gastrointest Endosc 1996; 43: 102 - 106

${ }^{23}$ Fritscher-Ravens A, Broering DC, Sriram PV, Topalidis T, Jaeckle S, Thonke F et al. EUS-guided fine-needle aspiration cytodiagnosis of hilar cholangiocarcinoma: a case series. Gastrointest Endosc 2000; 52: $534-540$

${ }^{24}$ Fritscher-Ravens A, Broering DC, Knoefel WT, Rogiers X, Swain P, Thonke $\mathrm{F}$ et al. EUS-guided fine-needle aspiration of suspected hilar cholangiocarcinoma in potentially operable patients with negative brush cytology. Am J Gastroenterol 2004; 99: 45-51

25 Eloubeidi MA, Chen VK, Jhala NC, Eltoum IE, Jhala D, Chhieng DC et al. Endoscopic ultrasound-guided fine needle aspiration biopsy of suspected cholangiocarcinoma. Clin Gastroenterol Hepatol 2004; 2: 207-208

${ }^{26}$ Byrne MF, Gerke H, Mitchell RM, Stiffler HL, McGrath K, Branch MS et al. Yield of endoscopic ultrasound-guided fine-needle aspiration of bile duct lesions. Endoscopy 2004; 36: 715 -719 